\title{
Sub-Tenon's anesthesia: an update
}

This article was published in the following Dove Press journal:

Local and Regional Anesthesia

19 June 2012

Number of times this article has been viewed

\section{Philip Guise}

Auckland City Hospital, Auckland, New Zealand
Correspondence: Philip Guise,

Department of Anesthesia, Auckland City Hospital, Park Rd, Auckland I I48, New Zealand

Email philg@adhb.govt.nz
Abstract: Sub-Tenon's block has become the most common technique of orbital regional anesthesia in many centers. It provides effective anesthesia to the orbit with a lower incidence of sight-threatening complications than sharp needle techniques. This article will discuss the relevant anatomy, finer points of sub-Tenon's block technique, and the evidence supporting its safety.

Keywords: anesthesia local, anesthesia ophthalmic, sub-Tenon's block, techniques, complications

\section{Introduction}

Sub-Tenon's block (STB) was first described by Turnbull in $1884^{1}$ and later by Swan in $1956 .{ }^{2}$ It was revisited in the 1990 s by several workers including Hansen ${ }^{3}$ and Stevens, ${ }^{4}$ and has continued to become increasingly popular worldwide. It is now the most frequently performed regional orbital block in many countries, including New Zealand and the United Kingdom.

A 1-year national survey of current practices for cataract surgery in the UK in 2003 indicated that STB was used for $43 \%$ of cataract surgeries (up from 7\% in 1996), in comparison to $31 \%$ for peribulbar and $21 \%$ for topical anesthesia. ${ }^{5}$ Sub-Tenon's anesthesia has several theoretical advantages over sharp-needle techniques and evidence is continuing to accumulate indicating that these advantages are being realized in clinical practice. This article will summarize the relevant anatomy, techniques, advantages and disadvantages and the current evidence supporting the safety and efficacy of sub-Tenon's anesthesia.

\section{STB technique}

STB is classified as an episcleral technique (as opposed to retrobulbar and parabulbar [peribulbar] approaches). Local anesthetic can be introduced via a needle or blunt probe. The medial canthal technique described by Ripart et $a 1^{6}$ was originally thought to be a parabulbar technique until subsequent CT studies showed that the local anesthetic solution actually entered the sub-Tenon's space. ${ }^{7}$ However, one of the major advantages of the sub-Tenon's approach is the avoidance of passing sharp needles into the orbit, hence the use of a blunt probe is the preferred approach. The block can be performed in any quadrant, ${ }^{3,8,9}$ but the single-injection inferonasal approach has the advantage of being away from the usual site of surgery and away from the insertion of the superior and inferior oblique muscles. ${ }^{4,10}$ 


\section{Anatomy}

Tenon's capsule is a dense, fibrous layer of elastic tissue surrounding the eye and extraocular muscles in the orbit (Figure 1). It originates at the limbus and extends posteriorly to the optic nerve and has sleeves along the extraocular muscles. The penetration of the rectus muscles divides Tenon's capsule into anterior and posterior portions. Anterior Tenon's capsule is adherent to episcleral tissue from the limbus posteriorly for approximately $10 \mathrm{~mm}$ and is fused with the intramuscular septum of the extraocular muscles and overlying bulbar conjunctiva over most of this portion. Posterior Tenon's capsule is thinner and passes round to the optic nerve separating the globe from the contents of the retrobulbar space. Hence, there is potentially a space posteriorly between the sclera and Tenon's capsule. Delivery of local anesthetic into this space allows spread along the extraocular muscle sheaths, diffusion into the retrobulbar space, spread into the fascial planes around the lids, as well as a direct action on the nerves supplying the globe that pass through this space.

\section{Method}

The equipment required to perform STB consists of a lid speculum (eg, Kratz Barraquer), small forceps (eg, Hoskins-style notched tip), curved blunt-tipped spring scissors (eg, blunt Westcott), and a curved blunt-tipped cannula (eg, Stevens) all prepared sterile.

After placement of intravenous access and monitoring with pulse oximetry, local anesthetic drops such as proxymetacaine $0.5 \%$ or oxybuprocaine $0.4 \%$ are applied twice to the conjunctiva. After placement of a Kratz-Barraquer lid speculum and application of a third set of local anesthetic drops, the conjunctiva is cleansed with $4 \%$ (half strength) povidone iodine solution. The fused conjunctiva and anterior Tenon's capsule is picked up at an infero-nasal point $7-10 \mathrm{~mm}$ from the limbus, midway between the insertions of the medial and inferior rectus muscles. After making a small cut, the sub-Tenon's space is accessed using the closed blunt Westcott scissors to create a thin channel just past the equator of the globe to the posterior sub-Tenon's space.

A blunt-tipped cannula is then inserted into the posterior sub-Tenon's space and approximately $4 \mathrm{~mL}$ of local anesthetic introduced (Figure 2). Gentle constant digital pressure over the closed lids with two fingers, one of which is over the point where the conjunctival cut was made, is applied for 2-3 minutes.

Ultrasound studies have shown that after initial injection of local anesthetic into the sub-Tenon's space, the fluid spreads

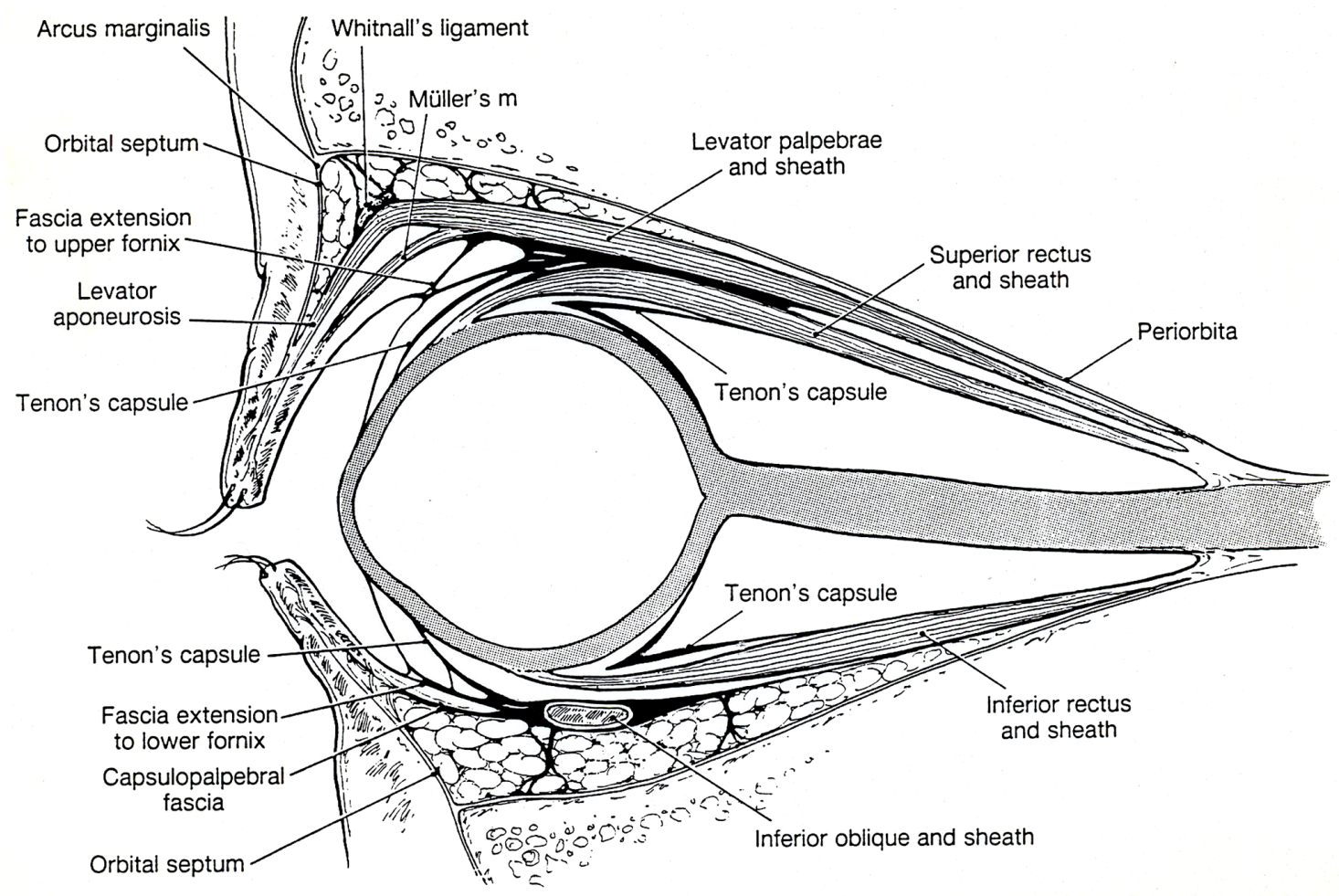

Figure I Anatomy of Tenon's capsule. Copyright @ 1984, Williams and Wilkins. Reproduced with permission from Doxanas MT, Anderson RL. Clinical Orbital Anatomy. Baltimore: Williams and Wilkins; 1984:109. 


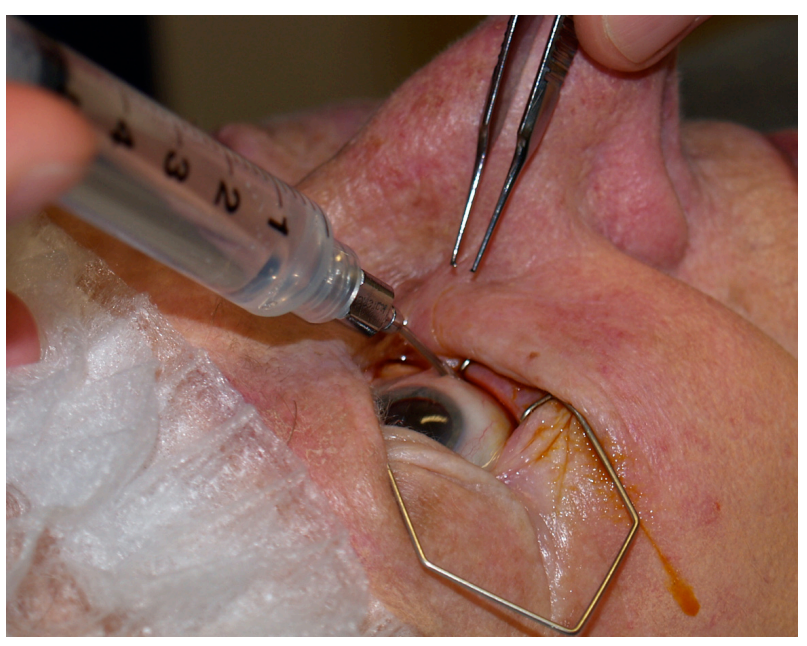

Figure 2 Sub-Tenon's block.

circumferentially around the posterior pole of the eye, bathing the area containing the ciliary nerves and producing what is described as a "T-sign."11 This accounts for the early globe analgesia, which occurs within 3 minutes. Over the next 5 minutes, local anesthetic solution diffuses across posterior Tenon's capsule into the retrobulbar space, along the extra-ocular muscle sheaths, the anterior sub-Tenon's space, and into the eyelids (producing an orbicularis block). These multiple sites of action account for the impressive reliability of this block. Onset of analgesia and orbicularis block takes 1-3 minutes with a mean onset of globe akinesia of 7 minutes.

\section{Finer points of technique}

\section{Use half-strength povidone iodine}

Not only does half-strength povidone iodine cleanse the conjunctiva for the block, but it may also reduce the incidence of endophthalmitis postoperatively. ${ }^{12}$

\section{Stay on the "line of longitude"}

Imagine that the globe has lines of longitude from front pole to back pole. Access to the sub-Tenon's space will be midway between medial and inferior recti, and it is important to stay equidistant from both recti as the Westcott scissors pass into the posterior sub-Tenon's space.

\section{Keep the Westcotts closed}

A cutting action should only be used to make the initial entry into the sub-Tenon's space, thereafter a blunt probing action is all that is required to pass the sclera-Tenon's bridging fibers at the equator. There is only one documented scleral perforation with STB, and this was a result of the surgeon using a cutting action in an attempt to dissect adhesions in the sub-Tenon's space from previous vitreo-retinal surgery. ${ }^{13}$

\section{Keep the tip of the cannula tight against the sclera}

The globe is a compressed sphere that measures on average only $23 \mathrm{~mm}$ from front to back. From the point of incision (7-10 $\mathrm{mm}$ from the limbus) one is already about $10 \mathrm{~mm}$ from the anterior plane of the globe, leaving only $13 \mathrm{~mm}$ before reaching the posterior plane. It is easy to misjudge the acuteness of the scleral curvature and overshoot, passing deep into the orbit and stretching Tenon's posteriorly, which is very uncomfortable for the patient. This can also occlude the end of the sub-Tenon's cannula, making it difficult to inject: the remedy is to pull the tip of the cannula against the back of the globe as though one was "hooking out the eye." This will allow easy injection and will produce less chemosis than simply withdrawing the cannula back along the entry track.

\section{Inject in different directions}

Rotation of the syringe about its long axis will redirect the cannula, allowing injection of local anesthetic in different directions, aiding spread behind the eye, and helping to reduce chemosis.

\section{Avoid the pterygia}

Do not cut through a pterygium. Because of the folds of tissue there are six layers instead of two, which will make access to the sub-Tenon's space difficult. Furthermore, pterygia are very vascular and tend to bleed, creating a large sub-conjuctival hemorrhage. Identify the inferior edge of the pterygium, place the closed forceps on the globe below it, and slide up the surface of the globe pushing the pterygium to one side. This will allow access to normal conjunctiva at or close to the traditional sub-Tenon's access point.

\section{Care with scleral buckles}

Patients who have had previous vitreo-retinal surgery may have encircling bands sewn into the sub-Tenon's plane to manage retinal detachment. This may interfere with access and risk damaging the globe. Buckles in the inferior nasal quadrant are not common as this is an unusual site for detachments, so one is normally able to access the sub-Tenon's space at this point. If the buckle is in the inferior nasal quadrant an infero-lateral approach to the sub-Tenon's space may be required. In patients with previous vitreo-retinal surgery, the sub-Tenon's space may be more adherent to sclera, and more careful blunt dissection may be required. It is important 
to avoid a cutting action to get through adhesions as this risks scleral perforation. In rare instances, the sub-Tenon's space may be so scarred as to make safe access impossible, and an alternative local anesthetic technique may be required.

\section{Keep the local anesthetic posterior to the equator}

Placement of local anesthetic posteriorly is the key to an effective block. Ensure that the channel created with the Westcott scissors is as narrow as possible by keeping the blades closed during dissection. This will minimize efflux of local anesthetic back along the channel.

\section{Reduce rate and force of injection}

The posterior sub-Tenon's space is a potential space containing vessels and nerves. If the expansion of this space by local anesthetic solution is too rapid this will produce pain, increase the tendency for chemosis, and potentially damage the fine neural structures that traverse this space. Injection speed should be around $1 \mathrm{~mL}$ per three seconds.

\section{Use less than $5 \mathrm{~mL}$ local anesthetic}

A rise in intraocular pressure (IOP) from volume effects in the orbit may reduce the depth of the anterior chamber, making surgical access more difficult. A study by Sohn et al found that injectate volumes above $5 \mathrm{~mL}$ produced significant rises in IOP. ${ }^{14}$ Other work by Gil et al using a 2-quadrant technique with two $5 \mathrm{~mL}$ injections showed a prolonged duration of analgesia with no significant rise in IOP in comparison to a single $5 \mathrm{~mL}$ injection, although there was a higher incidence $(52 \%)$ of chemosis. ${ }^{15}$

\section{Avoid ocular massage}

Massaging of the globe in an attempt to disperse the local anesthetic solution has been shown to cause peaks in IOP of up to $400 \mathrm{mmHg}^{16}$ and is associated with reports of bleeding in the anterior chamber. ${ }^{17}$ Gentle, steady pressure on the globe with a finger resting over the incision site will reduce local subconjunctival bleeding, but massage should not be performed.

\section{Choice of cannula}

Available cannulae fall into two broad groups: long and short.

\section{Long cannulae}

Examples of these include the Stevens-type (Beaver-Visitec, Waltham, MA) metal cannula ${ }^{4}$ (Figure 3) and the KumarDodds plastic cannula (Figure 4 ), ${ }^{18}$ which are shaped to

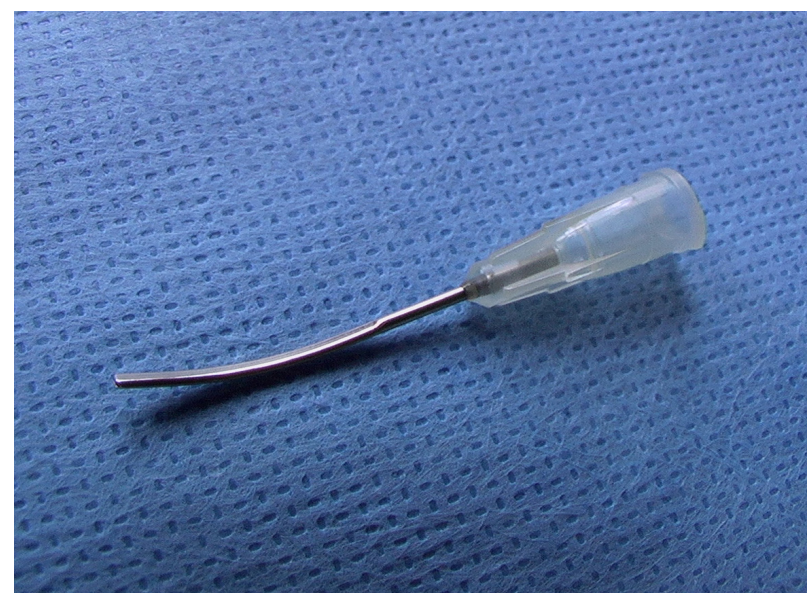

Figure 3 BD Visitec cannula (Beaver-Visitec, Waltham, MA).

deposit local anesthetic solution well posterior to the globe equator. The tips are blunt to minimize damage to structures in the posterior sub-Tenon's space. The Stevens design also has a flattened tip to facilitate keeping the cannula tip in contact with sclera as it is passed round the posterior part of the globe.

\section{Short cannulae}

Examples of these include the Greenbaum ${ }^{19}$ (Figure 5) and "ultrashort" cannula (Figure 6). ${ }^{20}$ Potential advantages of shorter cannulae include reduced risk of trauma to structures behind the globe. However, the anterior injection point predisposes to increased chemosis and a more rapid rate of injection is required, which could generate shear forces, traumatizing the delicate neural structures in the posterior sub-Tenon's space. Faster injection is also more uncomfortable for the patient.

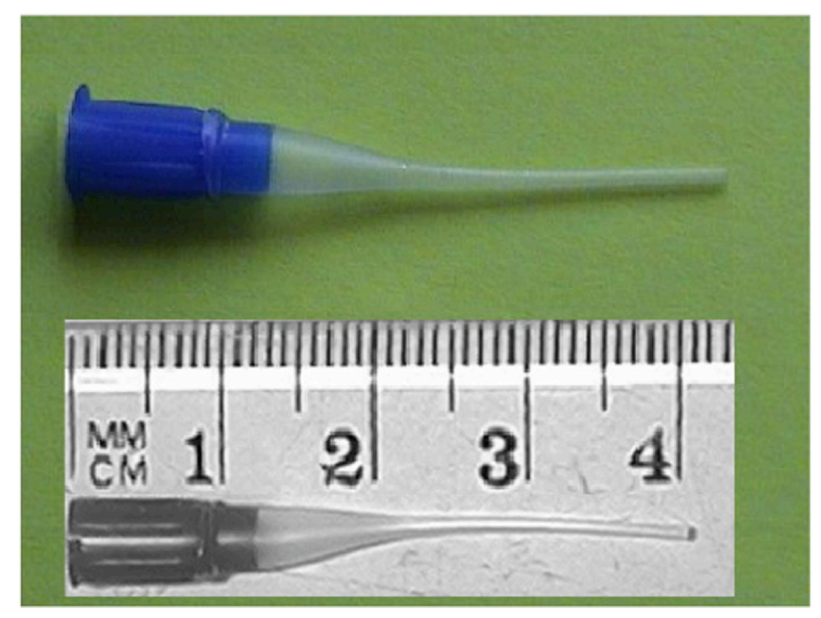

Figure 4 Kumar-Dodds cannula. Copyright (c) 200I, John Wiley and Sons. Reproduced with permission from Kumar CM, Dodds C. A disposable plastic subTenon cannula. Anaesthesia. 200 I;56(4):399.18 


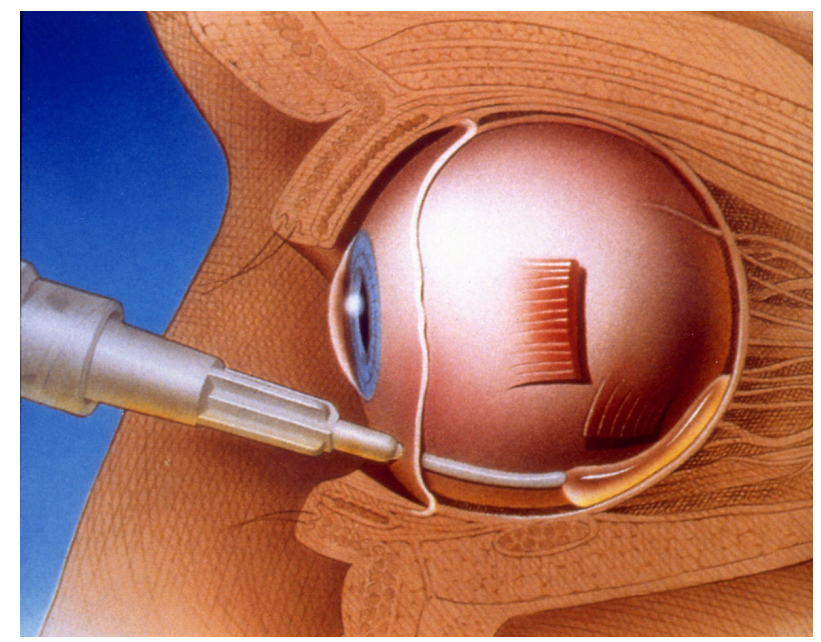

Figure 5 Greenbaum cannula. Copyright (C) 2000. Alcon Laboratories, Fort Worth, TX. Reproduced with permission.

\section{Indications for sub-Tenon's anesthesia}

Sub-Tenon's block is suitable for the majority of ophthalmic surgical procedures including cataract surgery, vitreoretinal surgery, ${ }^{21}$ trabeculectomy, ${ }^{22}$ adult strabismus surgery, ${ }^{23}$ panretinal photocoagulation, ${ }^{24}$ optic nerve sheath fenestration, ${ }^{25}$ long-term postoperative pain management, ${ }^{26}$ and therapeutic delivery of drugs. ${ }^{27}$

\section{Contraindications for sub-Tenon's anesthesia}

There are relatively few contraindications for sub-Tenon's anesthesia. Absolute contraindications would include patient refusal, inability to cooperate, and infection at the injection site.

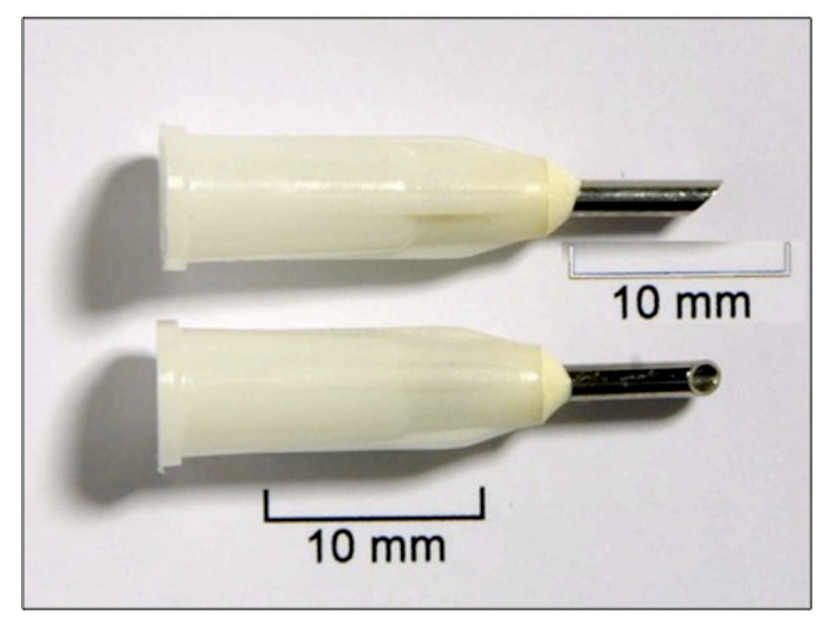

Figure 6 Ultrashort cannula. Copyright (C) 2004. Elsevier. Reproduced with permission from McNeela BJ, Kumar CM. Sub-Tenon's block with an ultrashort cannula. J Cataract Refract Surg. 2004;30(4):858-862. ${ }^{20}$
Careful consideration is required in patients who are unable to lie flat, are profoundly deaf, or have a marked head tremor. General anesthesia may be preferable in these cases.

\section{Advantages of sub-Tenon's anesthesia}

The advantages of sub-Tenon's anesthesia are summarized in Table 1.

\section{Less painful than traditional blocks}

A study on 6000 sub-Tenon's blocks found that over $68 \%$ of patients had no discomfort at all during performance of the block and less than $1.5 \%$ reported more than mild to moderate pain. ${ }^{28}$ This was in contrast to patients having a retrobulbar block. STB is also more comfortable to perform than peribulbar block. ${ }^{29}$

\section{Good intraoperative analgesia}

A comparison of the quality of analgesia between topical, retrobulbar, and sub-Tenon's techniques found that $99 \%$ of subTenon's patients had complete intraoperative analgesia compared to $83 \%$ of retrobulbar and $69 \%$ of topical patients. ${ }^{8}$

\section{Good akinesia}

The degree of akinesia has been found to be better in patients who received sub-Tenon's when compared with patients who received retrobulbar techniques. ${ }^{28}$

\section{Avoidance of passage of sharp needles into the orbit}

The tips of the Westcott scissors are not capable of penetrating normal sclera as long as a cutting action is avoided while accessing the sub-Tenon's space.

\section{Low risk of sight-threatening complications}

Anecdotally, over 35,000 sub-Tenon's blocks have been performed in the author's region with no sight-threatening complications. This compares well with the best results obtained with sharp needle techniques. ${ }^{30}$

\section{Safer in anticoagulated patients}

Studies have shown that the incidence of minor sub-conjunctival hemorrhage is increased in patients on aspirin, clopidogrel, and warfarin, but there is no increase in major hemorrhages. ${ }^{28,31}$ There is currently no data to support the safety of sub-Tenon's anesthesia in patients taking dabigatran (Pradaxa ${ }^{\circledR}$; Boehringer Ingelheim Pharma 
Table I Advantages and disadvantages of sub-Tenon's block

\begin{tabular}{ll}
\hline Advantages & Disadvantages \\
\hline Virtually painless & $\begin{array}{l}\text { Subconjunctival hemorrhage } \\
\text { Chemosis } \\
\text { Good analgesia }\end{array}$ \\
Good akinesia & Care with scleral buckles \\
Avoids complications & Associated with rare reports of \\
of sharp needles & sight-threatening complications \\
Low risk of serious complications & \\
No facial block required & \\
Safer in anticoagulated patients & \\
Safe in eyes with long axial length & \\
Minimal/no rise in IOP &
\end{tabular}

Abbreviation: IOP, intraocular pressure.

$\mathrm{GmbH}$ and $\mathrm{Co}, \mathrm{KG}$, Ingelheim am Rhein, Germany), and recommendations are to withhold this drug for two to five days prior to surgery. ${ }^{32}$

\section{Safe in patients with long axial length}

Because of the avoidance of instruments that can penetrate sclera, long axial length and associated posterior staphylomas do not pose a risk with the sub-Tenon's technique.

\section{Minimal/no rise in intraocular pressure}

STB using less than $5 \mathrm{~mL}$ produces little or no rise in IOP. $^{33,34}$

\section{Complications of sub-Tenon's anesthesia}

(Table 1). Many of the complications of STB are the same as those of peribulbar and retrobulbar blocks. However, there is now evidence that the incidence of serious sightthreatening complications is lower with the sub-Tenon's technique. ${ }^{5,28}$

Minor complications include:

\section{Subconjunctival hemorrhage}

Subconjunctival hemorrhage is the most frequent minor complication with a reported incidence of $7 \%-100 \%$. The majority of hemorrhages are small (confined to 1 quadrant) and purely cosmetic, causing no interference with surgery. Larger bleeds may be caused by damage to vortex veins in the posterior sub-Tenon's space. Minor hemorrhages are more frequent in anticoagulated patients but do not appear to be of any greater severity than in patients not taking anticoagulants. STB produces a sympathetic nerve block and the resulting loss of vasomotor control can give the impression of sub-conjunctival blood, which may account for the high incidence reported in some studies. In one study, $7 \%$ of patients had a sub-conjunctival hemorrhage that was noticeable but did not interfere with surgery. ${ }^{28}$ Only one case in 6000 was severe enough to warrant cancellation of the surgery. The incidence of sub-conjunctival hemorrhage can be reduced by careful dissection, avoiding conjunctival vessels, not passing the Westcott scissors farther than the sclera-Tenon's bridging fibers at the equator of the globe, or opening the blades when accessing the sub-Tenon's space. Gentle digital pressure can also be applied on the lower eyelid over the site of the sub-Tenon's space access for 2-3 minutes after injection.

A study by Gauba et al in 2007, looking at the use of bipolar conjunctival cautery prior to conjunctival incision, demonstrated a significant reduction in sub-conjunctival hemorrhage, especially in patients taking anticoagulants. ${ }^{35}$ However, caution with the use of cautery is advised, as it may create a conjunctival hole, which may be slow to heal because of the cauterized edges.

\section{Chemosis}

Some local anesthetic solution can spread into the anterior sub-Tenon's region causing ballooning of the conjunctiva. The incidence is reported as being between $5.6 \%$ and $60 \%$ with a long cannula. 9,28 This can be minimized by ensuring the local anesthetic solution is deposited predominantly in the posterior sub-Tenon's space (eg, injecting in different directions by rotation of the syringe about its long axis) and applying gentle digital pressure (not massage) to the eye for 3-5 minutes after placement of the block.

\section{Retained visual sensations}

Patients having cataract surgery under any local technique report a variety of visual sensations including flashes of light, colors, movements, and surgeon's fingers. ${ }^{36-39}$ The incidence of these phenomena appears not to differ significantly between retrobulbar, peribulbar, sub-Tenon's, and topical techniques. Most patients are unconcerned or even enjoy the phenomenon, but up to $16 \%$ interpret the experience as unpleasant. ${ }^{37}$ It is therefore useful to warn patients of this preoperatively.

Other more serious complications of sub-Tenon's blocks are rare:

\section{Extraocular muscle paresis}

It is not unusual for the patient to experience transient postoperative strabismus lasting a few days following surgery. However, there are a small number of isolated cases of long standing strabismus, usually involving the inferior rectus. Splerer and Schwalb have reported a superior oblique palsy that resolved 
after one month, ${ }^{40}$ while Merino et al reported eight cases of extraocular muscle dysfunction lasting more than 6 months, four of which required strabismus surgery. ${ }^{41}$ It is to be noted that all cases received an STB using 5\% lignocaine, which is concentrated enough to cause direct myotoxicity. Similarly, in the three case reports by Jaycock et al, two cases received $4 \%$ lignocaine and $0.75 \%$ bupivacaine, while the third case received $2 \%$ lignocaine without hyaluronidase. ${ }^{42}$ Direct trauma to the extraocular muscle (resulting from failure to remain on the "line of longitude" midway between the medial and inferior rectus muscles in the inferonasal approach) may also have been a factor. Myotoxicity problems appear to be higher if hyaluronidase is not used..$^{43,44}$

\section{Optic neuropathy}

All regional anesthetic techniques including retrobulbar, peribulbar, and STB have been shown to reduce ocular pulse amplitude for at least 10 minutes following performance of the block. ${ }^{34,45}$ This reduction occurs in the absence of a rise in IOP. There are a small number of reported cases in the literature of ischemic optic neuropathy resulting in loss of vision. ${ }^{46,47} \mathrm{~A}$ common feature of these cases is that the majority were associated with non-intraocular procedures (eg, pterygium, strabismus surgery) such that the eye was not opened and therefore IOP was not made atmospheric during the procedure. Fiebel and Guyton also reported two cases of transient central retinal artery occlusion following STB, both of which resolved spontaneously before surgery. ${ }^{47}$ The reason for this remains unclear but it has been postulated that this was either due to localized mechanical pressure from the bolus of local anesthetic, or direct vasoconstriction caused by the local anesthetic.

\section{Retrobulbar hemorrhage}

There are two reported cases of retrobulbar hemorrhage following STB. ${ }^{48,49}$ In one of the two cases the patient was on combined antiplatelet agents (aspirin and clopidogrel).

\section{Central spread}

Some anatomical studies of the sub-Tenon's space indicate that it may be a lymphatic space that drains along the optic nerve sheath, so it is possible that local anesthetic could spread along the optic nerve sheath. Also, accidental perforation of the optic nerve sheath due to excessively deep dissection with the Westcott scissors is theoretically possible. There have been two cases of transient loss of consciousness ${ }^{17}$ and one death possibly caused by central spread of local anesthetic to the brain stem following STB. ${ }^{50}$ It must be borne in mind that this complication is much rarer than with a retrobulbar block.

\section{Orbital cellulitis}

There are currently only two reports of orbital cellulitis following sub-Tenon's block. One patient had an active corneal infection at the time, ${ }^{51}$ and in the other case the surgeon did not use povidone-iodine prior to performing the block. ${ }^{52}$

\section{Scleral perforation}

There is one reported case of ocular perforation during STB. In this instance, a cutting action with the Westcott scissors was employed due to scarring of the sub-Tenon's space from previous surgery. ${ }^{13}$ As was noted previously, it is important not to open the scissors once the initial cut is made to access the sub-Tenon's space. If access is not possible due to scarring, alternative forms of anesthesia should be considered.

\section{Hyphema}

Bleeding into the anterior chamber has been reported, with this appearing to be due to ocular massage following local anesthetic injection. ${ }^{17}$ Ocular massage can cause transient rises in IOP up to $400 \mathrm{mmHg}$ and should not be performed. ${ }^{16}$

\section{Choice of local anesthetic solutions for sub-Tenon's anesthesia}

There are many variations of local anesthetic agents and adjuvants that have been employed in sub-Tenon's anesthesia over the decades, and a detailed discussion of these is beyond the scope of this article. The author's "standard" solution is a mixture of $2 \%$ plain lignocaine, $0.5 \%$ plain bupivacaine, and $150 \mathrm{iu}$ hyaluronidase. The rationale for this choice is that the lignocaine and hyaluronidase provide a rapid onset of block, while bupivacaine has a slower onset but longer duration to provide postoperative analgesia. This combination will provide approximately 60-90 minutes of surgical anesthesia and 4-6 hours of postoperative analgesia.

Other options include $2 \%$ lignocaine/150 iu hyauronidase, which will provide approximately 45 minutes of surgical anesthesia and is useful for short cases and faster cataract surgeons. It is also particularly advantageous in patients with no sight in the other eye as it will allow a faster return of vision and orbicularis function. A clear eye shield (rather than a pad and opaque shield) can be used to allow the patient some vision in the early postoperative period.

Alternatively, 1\% ropivacaine/150 iu hyaluronidase has an onset time comparable to a lignocaine/bupivacaine/ hyaluronidase mix but has the advantage of providing slightly longer (90-120 minutes) surgical anesthesia. This makes it 
particularly useful for vitreo-retinal procedures. This is less of an advantage for shorter cases as the prolonged period of akinesia and orbicularis block may allow an unsupervised padded eye to partly open, which could cause drying of the cornea. A theoretical disadvantage is that, unlike lignocaine and bupivacaine, ropivacaine has only weak antibacterial properties. $^{53}$

Other agents such as mepivacaine, ${ }^{54}$ etidocaine,${ }^{55}$ and prilocaine ${ }^{56}$ have all been reported to be effective, but little comparative data is available. ${ }^{57,58}$ Articaine is the most widely used local anesthetic for dental anesthesia in Italy, Germany, and the Netherlands, and has recently become available in the UK. There are some encouraging studies of its use in regional anesthesia of the orbit, indicating that it has a faster onset and greater motor block than lignocaine..$^{59,60}$

\section{Hyaluronidase}

This is an enzyme derived from sheep (ovine) that reversibly depolymerises hyaluronic acid, one of the chief components of the extracellular matrix. This allows easier spread of local anesthetic solutions through connective tissue planes. The agent is presented as a freeze-dried powder of $1500 \mathrm{iu}$ (Hyalase $^{\circledR}$; Wockhardt UK Ltd, Wrexham, UK) and can be reconstituted in any local anesthetic solution to create a dilution of $150 \mathrm{iu} / \mathrm{mL}$. A non-ovine recombinant preparation (Hylenex; Halozyme Therapeutics Inc, San Diego, CA) is also available in some countries. The usual dose is 150 iu in total, but there are reports of much lower doses (25 iu) being effective. ${ }^{61}$

\section{Advantages}

Controlled trials have shown that the addition of hyaluronidase significantly accelerates the onset of globe akinesia but does not improve the final block quality, ${ }^{62}$ and may also reduce the incidence of transient postoperative extraocular muscle paresis. During a period of unavailability of hyaluronidase, a series of reports appeared in the literature citing prolonged recovery of extraocular muscle function. . $33,44^{4}$ However, no studies looking specifically at this issue in STB have been conducted.

\section{Disadvantages}

There is a risk of allergic reaction associated with STB, but this is rare. Reports of immediate hypersensitivity are very uncommon, ${ }^{63}$ with a delayed hypersensitivity reaction 12-72 hours postoperatively more likely; this presents as orbital redness and swelling that may be confused with infective orbital cellulitis. ${ }^{64,65}$ The two diagnoses can be distinguished by hyaluronidase reaction having a negative microbiology and responding rapidly to steroids. Allergy can be later confirmed by skin-prick testing.

\section{Other adjuvants}

Other additives to the local anesthetic have been reported. Alkalinization with sodium bicarbonate appears to accelerate the onset of peribulbar block but not sub-Tenon's block..$^{66-68}$ The use of vasoconstrictors (eg, adrenaline) is not recommended due to the potential for these to further lower ocular blood flow. ${ }^{69}$ The addition of clonidine and muscle relaxants have also been described. ${ }^{70-72}$

\section{Perioperative care}

A set of comprehensive guidelines for patients having cataract surgery can be found on the Royal College of Ophthalmologists' website ${ }^{73}$ and in the guidelines of the Royal College of Anaesthetists. ${ }^{74}$

Prior to presenting for surgery, the patient should complete a comprehensive health questionnaire. This should include whether the patient is able to lie flat, an assessment of their anxiety levels, and a full drug and allergy history. This is best done in the outpatient clinic when a decision to operate is made and the date for surgery scheduled. Any hearing difficulties should also be noted, as patients who are totally deaf may require general anesthesia due to their inability to sign or lip-read whilst under a surgical drape intraoperatively.

The patients' vital signs should also be checked while at the outpatient clinic so that abnormal vital signs can be assessed and treated prior to admission. Guidelines for patient management should be established throughout the medical and nursing services involved in ophthalmic care so that a consistent approach can be taken towards the patient's perioperative management. For example, with regard to the management of hypertension, there is no evidence to support cancelling operations on patients with a blood pressure under $180 / 110 .^{75}$

There is no evidence to support "routine" preoperative investigations in patients having local anesthesia. A prospective randomized study of over 19,000 cataract operations under local anesthesia found no difference in perioperative events between the 9600 patients who had preoperative ECG, full blood, urea, electrolyte, and glucose tests, and the 9400 who had no preoperative testing. ${ }^{76}$

Investigations should only be ordered if they would affect the decision to proceed with the planned surgery, influence the type of anesthesia used, alter the care plan, or 
be indicated even in the absence of surgery, such as a history of worsening angina. This means that the only investigations normally required for patients having eye surgery under STB would be a blood glucose test on admission in diabetics and an INR within 5 days prior to surgery for patients on warfarin.

\section{Management of the anticoagulated patient}

Insertion of an STB has been shown to be safe in patients taking aspirin, warfarin, and clopidogrel, although the incidence of minor sub-conjunctival hemorrhage is increased..$^{28,31}$ The Royal College of Ophthalmologists' guidelines recommend STB (or topical anesthesia) for anticoagulated patients in preference to sharp-needle techniques. ${ }^{73}$

There is currently no data available on the safety of STB in patients taking the direct thrombin inhibitor dabigatran (Pradaxa $^{\circledR}$; Boehringer Ingelheim Pharma $\mathrm{GmbH}$ and $\mathrm{Co}$, $\mathrm{KG})$. The concern with this drug in the surgical setting is that measurement of the degree of anticoagulation is not accurately indicated in routine anticoagulant tests and there is no established "therapeutic range" for the degree of anticoagulation. Also, in the acute setting, the anticoagulant effect is irreversible. Dabigatran is renally excreted and its duration of action is prolonged in patients with impaired creatinine clearance (eg, elderly patients and diabetics). Until further data is available, it is recommended that this drug be stopped for between 2 and 5 days prior to surgery. ${ }^{32}$

\section{Preoperative fasting}

With the relative safety of local anesthesia, particularly topical and sub-Tenon's techniques, it is not necessary to starve patients preoperatively. This has major advantages, particularly to diabetic patients who are able to continue food and medications as usual on the day of surgery. Also, it does not preclude the administration of small doses of anxiolytic medication in the perioperative period. ${ }^{28}$ However, patients who are likely to require heavy sedation or may require conversion to general anesthesia should be fasted appropriately.

\section{Supervised anesthesia care}

During surgery, patients should be comfortable, conscious, and free of anxiety and pain. To ensure this, effective local anesthesia is necessary, but it is also important to check that the patient is positioned comfortably, is warm, and has sufficient oxygen flow under the surgical drapes to prevent hypoxia and hypercarbia. Language difficulties can be overcome by having a relative or interpreter in theater. Intraoperative monitoring should include pulse oximetry and ECG.

Appropriate equipment and skilled personnel must be available to deal safely with any adverse events that may arise from the patient's pre-existing medical conditions, anesthetic drugs, and techniques. Small amounts of intravenous sedation (eg, less than $2 \mathrm{mg}$ of midazolam) can be given to non-fasted patients with no untoward effects; however intravenous sedation should only be administered under the supervision of an anesthetist, whose sole responsibility is to that operating list.

\section{Administration of STBs}

In the majority of situations, appropriately trained anesthetists or ophthalmologists perform STB. However, nurse specialists/nurse practitioners have been trained to perform STB in some centers. ${ }^{77}$ In Auckland, New Zealand, a specific training course for nurse specialists in sub-Tenon's anesthesia has been implemented and there are currently three nurses performing STB for cataract surgery (without intravenous sedation) under the supervision of an anesthetist, who is available on the operating theater floor, but not exclusively for that theater.

\section{Intravenous access}

There is debate regarding the necessity for indwelling intravenous access in patients having $\mathrm{STB},{ }^{78}$ and the Royal College of Anaesthetists' guidelines allow intravenous access to be at the practitioner's discretion. ${ }^{74}$ However, in the author's opinion, while vasovagal episodes, unexpected need for administration of intravenous sedation, and cardiac arrhythmias occur infrequently, these are of sufficient impact in the perioperative period as to make routine insertion of an intravenous line good clinical practice. This view has been supported by other authors. ${ }^{79}$

\section{Topical versus sub-Tenon's anesthesia}

Studies comparing sub-Tenon's techniques with topical anesthesia indicate that STB provides superior analgesia, ${ }^{80}$ is associated with a lower posterior capsule rupture rate, ${ }^{81}$ and results in greater patient satisfaction. ${ }^{82}$

\section{Incidence of sight-threatening complications with STB}

A 2007 study of 375,000 patients having cataract surgery in the UK (of whom 161,000 had an STB) indicated that the reported incidence of sight-threatening complications associated with STB is less than 0.6 per 10,000 cases. ${ }^{5}$ 
This figure compares very favorably to those for peribulbar (2.9 per 10,000) and retrobulbar techniques (4.5 per 10,000).

This was further supported in a study that found a $60 \%$ reduction in the incidence of serious complications with STB in comparison to peribulbar anesthesia, with 5 serious complications reported per 10,000 patients in the STB group compared with 12 per 10,000 in the peribulbar group. ${ }^{83}$ However, minor complications in the STB group (such as chemosis [2.03\%] and sub-conjunctival hemorrhage $[1.99 \%])$ were more common than in the peribulbar group.

These data indicate that STB is safer than sharp needle techniques and, by virtue of lower intraoperative surgical complications, is safer than topical techniques. The benefits of STB therefore significantly outweigh the small risks associated with the technique.

\section{Conclusion}

STB is continuing to gain in popularity and is now the most popular technique of regional orbital anesthesia in many centers. It provides extremely good analgesia and operating conditions, while avoiding the passage of sharp needles into the orbit. The risk of serious complications is very low, and studies have shown that their incidence is much lower than with other techniques of ocular regional anesthesia.

\section{Disclosure}

The author reports no conflicts of interest in this work.

\section{References}

1. Turnbull CS. The hydrochlorate of cocaine, a judicious opinion of its merits. Med Surg Rep. 1884;29:628-629.

2. Swan KC. New drugs and techniques for ocular anaesthesia. Trans Am Acad Ophthalmol Otolaryngol. 1956;60(3):368-375.

3. Hansen EA, Mein CE, Mazzoli R. Ocular anaesthesia for cataract surgery: a direct sub-Tenon's approach. Ophthalmic Surg. 1990;21(10): 696-699.

4. Stevens JD. A new local anaesthesia technique for cataract extraction by one quadrant sub-Tenon's infiltration. Br J Ophthalmol. 1992;76(11): 670-674.

5. Eke T, Thompson JR. Serious complications of local anaesthesia for cataract surgery: a 1 year survey in the United Kingdom. Br JOphthalmol. 2007;91(4):470-475.

6. Ripart J, Lefrant JY, Lalourcey L, et al. Medial canthus (caruncle) single injection periocular anesthesia. Anesth Analg. 1996;83(6): 1234-1238.

7. Ripart J, Metge L, Prat-Pradal D, Lopez FM, Eledjam JJ. Medial canthus single-injection episcleral (sub-Tenon anesthesia): computed tomography imaging. Anesth Analg. 1998;87(1):43-45.

8. Fukasaku H, Marron JA. Sub-Tenon's pinpoint anaesthesia. J Cataract Refract Surg. 1994;20(4):468-471.

9. Roman SJ, Chong Sit DA, Boureau CM, Auclin FX, Ullern MM. Sub-Tenon's anaesthesia: an efficient and safe technique. $\mathrm{Br} J$ Ophthalmol. 1997;81(8):673-676.
10. Guise PA. Single quadrant sub-Tenon's block. Evaluation of a new local anaesthetic technique for eye surgery. Anaesth Intensive Care. 1996;24(2):241-244.

11. Winder S, Walker SB, Atta H. Ultrasonic localization of anesthetic fluid in sub-Tenon's, peribulbar, and retrobulbar techniques. J Cataract Refract Surg. 1999;25(1):56-59.

12. Speaker MG, Menikoff JA. Prophylaxis of endophthalmitis with topical povidone-iodine. Ophthalmology. 2001;98(12):1769-1775.

13. Frieman BJ, Friedberg MA. Globe perforation associated with subtenon's anesthesia. Am J Ophthalmol. 2001;131(4):520-521.

14. Sohn HJ, Moon HS, Nam DH, Paik HJ. Effect of volume used in sub-Tenon's anesthesia on efficacy and intraocular pressure in vitroretinal surgery. Ophthalmologica. 2008;222(6):414-421.

15. Gil VS, Presland AH, Lord JA, Bunce C, Xing W, Charteris DG. Two-quadrant high-volume sub-Tenon's anaesthesia for vitrectomy: a randomised controlled trial. Br J Ophthalmol. 2012;96(2):189-192.

16. Ernest JT, Goldstick TK, Stein MA, Zheutlin JD. Ocular massage before cataract surgery. Trans Am Ophthalmol Soc. 1985;83:205-217.

17. Rüschen H, Bremner FD, Carr C. Complications after sub-Tenon's eye block. Anesth Analg. 2003;96(1):273-277.

18. Kumar CM, Dodds C. A disposable plastic sub-Tenon cannula. Anaesthesia. 2001;56(4):399-400.

19. Kumar CM, Dodds C. Evaluation of Greenbaum sub-Tenon's block. Br J Anaesth. 2001;87(4):631-633.

20. McNeela BJ, Kumar CM. Sub-Tenon's block with an ultrashort cannula. $J$ Cataract Refract Surg. 2004;30(4):858-862.

21. Kwok AK, Van Newkirk MR, Lam DS, Fan DS. Sub-Tenon's anesthesia in vitreoretinal surgery: a needleless technique. Retina. 1999;19(4): 291-296.

22. Buys YM, Trope GE. Prospective study of sub-Tenon's versus retrobulbar anaesthesia for inpatient and day-surgery trabeculectomy. Ophthalmology. 1993;100(10):1585-1589.

23. Steele MA, Lavrich JB, Nelson LB, Koller HP. Sub-Tenon's infusion of local anaesthetic for strabismus surgery. Ophthalmic Surg. 1992;23(1): $40-43$.

24. Stevens JD, Foss AJ, Hamilton AM. No-needle one-quadrant sub-tenon anaesthesia for panretinal photocoagulation. Eye (Lond). 1993;7(Pt 6): 768-771.

25. Rizzuto PR, Spoor TC, Ramocki JM, McHenry JG. Subtenon's local anesthesia for optic nerve sheath fenestration. Am J Ophthalmol. 1996;121(3):326-327.

26. Ghosh YK, Goodall KL. Postoperative pain relief in vitreoretinal surgery with subtenon Bupivacaine $0.75 \%$. Acta Ophthalmol Scand. 2005;83(1):119-120.

27. Inoue M, Takeda K, Morita K, Yamada M, Tangiawara Y, Oguchi Y. Vitreous concentrations of triamcinolone acetonide in human eyes after intravitreal or subtenon injection. Am J Ophthalmol. 2004;138(6): 1046-1048.

28. Guise P. Sub-Tenon anesthesia: a prospective study of 6,000 blocks. Anesthesiology. 2003;98(4):964-968.

29. Parkar T, Gogate P, Deshpande M, Adenwala A, Maske A, Verappa K. Comparison of subtenon anaesthesia with peribulbar anaesthesia for manual small incision cataract surgery. Indian J Ophthalmol. 2005; 53(4):255-259.

30. Davis DB II, Mandel MR. Efficacy and complication rate of 16,224 consecutive peribulbar blocks. A prospective multicenter study. J Cataract Refract Surg. 1994;20(3):327-337.

31. Kumar N, Jivan S, Thomas P, McLure H. Sub-Tenon's anesthesia with aspirin, warfarin, and clopidogrel. J Cataract Refract Surg. 2006;32(6): 1022-1025.

32. Pharmac (NZ). Dabigatran testing and perioperative management [updated June 13, 2011]. Available at http://www.pharmac.govt.nz/2011/06/13/ Dabigatran\%20testing\%20and\%20perioperative\%20 management.pdf. Accessed on February 28, 2012.

33. Alwirty A, Koshy Z, Browning AC, Kiel W, Holden R. The effect of sub-Tenon's anaesthesia on intraocular pressure. Eye (Lond). 2001;15(Pt 6):733-735. 
34. Pianka P, Weintraub-Padova H, Lazar M, Geyer O. Effect of sub-Tenon's and peribulbar anesthesia on intraocular pressure and ocular pulse amplitude. J Cataract Refract Surg. 2001;27(8): 1221-1226.

35. Gauba V, Saleh GM, Watson K, Chung A. Sub-Tenon anaesthesia: reduction in subconjunctival haemorrhage with controlled bipolar conjunctival cautery. Eye (Lond). 2007;21(11):1387-1390.

36. Rengaraj V, Radhakrishnan M, Au Eong KG, et al. Visual experience during phacoemulsification under topical versus retrobulbar anesthesia: results of a prospective, randomized, controlled trial. Am JOphthalmol. 2004;138(5):782-787.

37. Prasad N, Kumar CM, Patil BB, Dowd TC. Subjective visual experience during phacoemulsification cataract surgery under sub-Tenon's block Eye (Lond). 2003;17(3):407-409.

38. Wickremasinghe SS, Tranos PG, Sinclair N, Andreou PS, Harris ML, Little BC. Visual perception during phacoemulsification cataract surgery under subtenons anaesthesia. Eye (Lond). 2003;17(4):501-505.

39. Tan CS, Au Eong KG, Kumar CM. Visual experiences during cataract surgery: what anaesthesia providers should know. Eur J Anaesthesiol. 2005;22(6):413-419.

40. Spierer A, Schwalb E. Superior oblique muscle paresis after sub-Tenon's anesthesia for cataract surgery. J Cataract Refract Surg. 1999;25(1):144-145.

41. Merino P, Muñoz-Sanz N, Gómez-de-Liaño P, Gutiérrez-Partida B, Seijas-Leal O. Diplopia after sub-Tenon's anesthesia for cataract surgery [Article in Spanish]. Arch Soc Esp Oftalmol. 2006;81(3):141-146.

42. Jaycock PD, Mather CM, Ferris JD, Kirkpatrick JN. Rectus muscle trauma complicating sub-Tenon's local anaesthesia. Eye (Lond). 2001;15(Pt 5):583-586.

43. Brown SM, Brooks SE, Mazow ML, et al. Cluster of diplopia cases after periocular anesthesia without hyaluronidase. J Cataract Refract Surg. 1999;25(9):1245-1249.

44. Hamada S, Devys JM, Xuan TH, et al. Role of hyaluronidase in diplopia after peribulbar anesthesia for cataract surgery. Ophthalmology. 2005;112(5):879-882.

45. Findl O, Dallinger S, Menapace R, et al. Effects of peribulbar anesthesia on ocular blood flow in patients undergoing cataract surgery. Am J Ophthalmol. 1999;127(6):645-649.

46. Kim SK, Andreoli CM, Rizzo JF III, Golden MA, Bradbury MJ. Optic neuropathy secondary to sub-tenon anesthetic injection in cataract surgery. Arch Ophthalmol. 2003;121(6):907-909.

47. Feibel R, Guyton D. Transient central retinal artery occlusion after posterior sub-Tenon's anesthesia. J Cataract Refract Surg. 2003;29(9): 1821-1824.

48. Olitsky SE, Juneja RG. Orbital hemorrhage after the administration of sub-Tenon's infusion anesthesia. Ophthalmic Surg Lasers. 1997;28(2): 145-146.

49. Subbiah S, McGimpsey S, Best RM. Retrobulbar hemorrhage after sub-Tenon's anesthesia. J Cataract Refract Surg. 2007;33(9): $1651-1652$.

50. Quantock CL, Goswami T. Death potentially secondary to sub-Tenon's block. Anaesthesia. 2007;62(2):175-177.

51. Redmill B, Sandy C, Rose GE. Orbital cellulitis following corneal gluing under sub-Tenon's local anaesthesia. Eye (Lond) 2001;15(Pt 4):554-556.

52. Dahlmann AH, Appaswamy S, Headon MP. Orbital cellulitis following sub-Tenon's anaesthesia. Eye (Lond). 2002;16(2):200-201.

53. Aydin ON, Eyigor M, Aydin N. Antimicrobial activity of ropivacaine and other local anaesthetics. Eur J Anaesthesiol. 2001;18(10):687-694.

54. Ripart J, Lefrant J, L'Hermite J, et al. Caruncle single injection episcleral (Sub-tenon) anesthesia for cataract surgery: mepivacaine versus a lidocaine-bupivacaine mixture. Anesth Analg. 2000;91(1):107-109.

55. Sarvela J, Nikki P. Hyaluronidase improves regional ophthalmic anaesthesia with etidocaine. Can J Anaesth. 1992;39(9):920-924.

56. Manners TD, Burton RL. Randomised trial of topical versus sub-Tenon's local anaesthesia for small-incision cataract surgery. Eye (Lond). 1996;10(Pt 3):367-370.
57. Nicholson G, Sutton B, Hall GM. Ropivacaine for peribulbar anaesthesia. Reg Anesth Pain Med. 1999;24(4):337-340.

58. McLure HA, Kumar CM, Ahmed S, Patel A. A comparison of lignocaine $2 \%$ with levobupivacaine $0.75 \%$ for sub-Tenon's block. Eur J Anaesthesiol. 2005;22(7):500-503.

59. Allman KG, McFadyen JG, Armstrong J, Sturrock GD, Wilson IH. Comparison of articaine and bupivacaine/lignocaine for single medial canthus peribulbar anaesthesia. Br J Anaesth. 2001;87(4):584-587.

60. Gouws P, Galloway P, Jacob J, English W, Allman KG. Comparison of articaine and bupivacaine/lignocaine for sub-Tenon's anaesthesia in cataract extraction. Br J Anaesth. 2004;92(2):228-230.

61. Kallio H, Paloheimo M, Maunuksela EL. Hyaluronidase as an adjuvant in bupivacaine-lidocaine mixture for retrobulbar/peribulbar block. Anesth Analg. 2000;91(4):934-937.

62. Guise P, Laurent S. Sub-Tenon's block: the effect of hyaluronidase on speed of onset and block quality. Anaesth Intensive Care. 1999:27(2): 179-181.

63. Agrawal A, McLure HA, Dabbs TR. Allergic reaction to hyaluronidase after a peribulbar injection. Anaesthesia. 2003;58(5):493-494.

64. Liebovitch I, Tamblyn D, Casson R, Selva D. Allergic reaction to hyaluronidase: a rare cause of orbital inflammation after cataract surgery. Graefes Arch Clin Exp Ophthalmol. 2006;244(8):944-949.

65. Ahluwalia HS, Lukaris A, Lane CM. Delayed allergic reaction to hyaluronidase: a rare sequel to cataract surgery. Eye (Lond). 2003;17(2): 263-266.

66. Zahl K, Jordan A, McGroarty J, Gotta AW. pH-adjusted bupivacaine and hyaluronidase for peribulbar block. Anesthesiology. 1990;72(2): 230-232.

67. Zahl K, Jordan A, McGroarty J, Soresen B, Gotta AW. Peribulbar anesthesia. Effect of bicarbonate on mixtures of lidocaine, bupivacaine, and hyaluronidase with or without epinephrine. Ophthalmology. 1991;98(2):239-242.

68. Moharib MM, Mitra S. Alkalinized lidocaine and bupivacaine with hyaluronidase for sub-tenon's ophthalmic block. Reg Anesth Pain Med. 2000;25(5):514-517.

69. McLure HA, Rubin AP. Review of local anaesthetic agents. Minerva Anesthesiol. 2005;71(3):59-74.

70. Bharti N, Madan R, Kaul HL, Khokhar SK, Mishra S. Effect of addition of clonidine to local anaesthetic mixture for peribulbar block. Anaesth Intensive Care. 2002;30(4):438-441.

71. Reah G, Bodenham AR, Braithwaite P, Esmond J, Menage MJ. Peribulbar anaesthesia using a mixture of local anaesthetic and vecuronium. Anaesthesia. 1998;53(6):551-554.

72. Küçükyavuz Z, Arici M. Effects of atracurium added to local anesthetics on akinesia in peribulbar block. Reg Anesth Pain Med. 2002;27(5): 487-490.

73. The Royal College of Ophthalmologists [homepage on the Internet]. London: The Royal College of Ophthalmologists; 2010. Available from: http://www.rcophth.ac.uk/. Accessed March 6, 2012.

74. The Royal College of Anaesthetists [homepage on the Internet]. Guidelines for the provision of anaesthetic services. London: The Royal College of Anaesthetists; 2009. Available from: http://www.rcoa.ac.uk/ docs/GPAS.pdf. Accessed March 6, 2012.

75. Howell SJ, Sear JW, Foëx P. Hypertension, hypertensive heart disease and perioperative cardiac risk. Br J Anaesth. 2004;92(4):570-583.

76. Schein OD, Katz J, Bass EB et al. The value of routine preoperative medical testing before cataract surgery. Study of Medical Testing for Cataract Surgery. N Engl J Med. 2000;342(3):168-175.

77. Waterman H, Mayer S, Lavin MJ, Spencer AF, Waterman C. An evaluation of the administration of sub-Tenon local anesthesia by a nurse practitioner. Br J Ophthalmol. 2002;86(5):524-526.

78. Sidery M, Absalom A, Burton R. Sub-Tenon's block: are fasting and intravenous access necessary? Br J Anaesth. 2004;92(6):909.

79. Kumar CM, Dodds C, Fanning GL, editors. Ophthalmic Anaesthesia. Lisse, The Netherlands: Swets and Zeitlinger; 2002.

80. Chittenden HB, Meacock WR, Govan JA. Topical anaesthesia with oxybuprocaine versus sub-Tenon's infiltration with $2 \%$ lignocaine for small incision cataract surgery. Br J Ophthalmol. 1997;81(4):288-290. 
81. Davison M, Padroni S, Bunce C, Rüschen H. Sub-Tenon's anaesthesia versus topical anaesthesia for cataract surgery. Cochrane Database Syst Rev. 2007;3:CD006291.

82. Rüschen H, Celaschi D, Bunce C, Carr C. Randomised controlled trial of sub-Tenon's block versus topical anaesthesia for cataract surgery: a comparison of patient satisfaction. Br J Ophthalmol. 2005;89(3): 291-293.
83. El-Hindy N, Johnston RL, Jaycock P, et al. The Cataract National Dataset Electronic Multi-centre Audit of 55,567 operations: anaesthetic techniques and complications. Eye (Lond). 2009;23(1):50-55.

\section{Publish your work in this journal}

Local and Regional Anesthesia is an international, peer-reviewed, open access journal publishing on the development, pharmacology, delivery and targeting and clinical use of local and regional anesthetics and analgesics. The journal welcomes submitted papers covering original research, basic science, clinical studies, reviews \& evaluations, guidelines, expert opinion and commentary, case reports and extended reports. The manuscript management system is completely online and includes a very quick and fair peer-review system, which is all easy to use. Visit http://www.dovepress.com/testimonials.php to read real quotes from published authors.

Submit your manuscript here: http://www.dovepress.com/local-and-regional-anesthesia-journal 